\title{
Author Correction: Characterization of Nigerian breast cancer reveals prevalent homologous recombination deficiency and aggressive molecular features
}

Jason J. Pitt1,17, Markus Riester (10 2 ${ }^{2}$, Yonglan Zheng (10 ${ }^{3}$, Toshio F. Yoshimatsu (1) ${ }^{3}$, Ayodele Sanni ${ }^{4}$, Olayiwola Oluwasola ${ }^{5}$, Artur Veloso², Emma Labrot ${ }^{2}$, Shengfeng Wang ${ }^{3,6}$, Abayomi Odetunde7, Adeyinka Ademola ${ }^{8}$, Babajide Okedere ${ }^{7}$, Scott Mahan ${ }^{2}$, Rebecca Leary ${ }^{2}$, Maura Macomber ${ }^{2}$, Mustapha Ajani ${ }^{5}$, Ryan S. Johnson², Dominic Fitzgerald ${ }^{1}$, A. Jason Grundstad ${ }^{1}$, Jigyasa H. Tuteja ${ }^{1}$, Galina Khramtsova ${ }^{3}$, Jing Zhang ${ }^{3}$, Elisabeth Sveen ${ }^{3}$, Bryce Hwang ${ }^{2}$, Wendy Clayton ${ }^{3}$, Chibuzor Nkwodimmah $^{8}$, Bisola Famooto ${ }^{8}$, Esther Obasi ${ }^{4}$, Victor Aderoju9 9 , Mobolaji Oludara9 ${ }^{9}$,Folusho Omodele9 ${ }^{9}$ Odunayo Akinyele ${ }^{3}$, Adewunmi Adeoye ${ }^{5}$,

Temidayo Ogundiran ${ }^{8}$, Chinedum Babalola7,10, Kenzie Maclsaac ${ }^{2}$, Abiodun Popoola ${ }^{11}$, Michael P. Morrissey², Lin S. Chen ${ }^{12}$, Jiebiao Wang ${ }^{12}$, Christopher O. Olopade ${ }^{3}$, Adeyinka G. Falusi ${ }^{7}$, Wendy Winckler², Kerstin Haase (1) ${ }^{13}$, Peter Van Loo (10 ${ }^{13,14}$, John Obafunwa ${ }^{4}$, Dimitris Papoutsakis ${ }^{2}$, Oladosu Ojengbede ${ }^{15}$, Barbara Weber ${ }^{2}$, Nasiru Ibrahim ${ }^{9}$, Kevin P. White ${ }^{1,16}$, Dezheng Huo 3,12 , Olufunmilayo I. Olopade (D) ${ }^{1,3} \&$ Jordi Barretina (1) 2,18

Correction to: Nature Communications https://doi.org/10.1038/s41467-018-06616-0, published online: 16 Oct 2018

The original version of this Article contained an error in the author affiliations.

The affiliation of Kevin P. White with Tempus Labs, Inc. Chicago, IL, USA, was inadvertently omitted.

This has now been corrected in both the PDF and HTML versions of the Article.

Published online: 14 January 2019

\footnotetext{
${ }^{1}$ Institute for Genomics and Systems Biology, University of Chicago, Chicago, IL 60637, USA. ${ }^{2}$ Novartis Institutes for BioMedical Research, Cambridge, MA 02139, USA. ${ }^{3}$ Center for Clinical Cancer Genetics \& Global Health, Department of Medicine, University of Chicago, Chicago, IL 60637, USA. ${ }^{4}$ Department of Pathology and Forensic Medicine, Lagos State University Teaching Hospital, Ikeja, Lagos, Nigeria. ${ }^{5}$ Department of Pathology, University of Ibadan, Ibadan, Oyo, Nigeria. ${ }^{6}$ Department of Epidemiology and Biostatistics, School of Public Health, Peking University Health Science Center, Beijing 100191, China.

7 Institute for Advanced Medical Research and Training, College of Medicine, University of Ibadan, Ibadan, Oyo, Nigeria. ${ }^{8}$ Department of Surgery, University of Ibadan, Ibadan, Oyo, Nigeria. ${ }^{9}$ Department of Surgery, Lagos State University Teaching Hospital, Ikeja, Lagos, Nigeria. ${ }^{10}$ Department of Pharmaceutical Chemistry, University of Ibadan, Ibadan, Oyo, Nigeria. ${ }^{11}$ Oncology Unit, Department of Radiology, Lagos State University, Ikeja, Lagos, Nigeria. ${ }^{12}$ Department of Public Health Sciences, University of Chicago, Chicago, IL 60637, USA. ${ }^{13}$ The Francis Crick Institute, 1 Midland Road, London NW1 1AT, UK. ${ }^{14}$ Department of Human Genetics, University of Leuven, Oude Markt 13, Leuven 3000, Belgium. ${ }^{15}$ Centre for Population and Reproductive Health, College of Medicine, University of Ibadan, Ibadan, Oyo, Nigeria. ${ }^{16}$ Tempus Labs, Inc., Chicago, IL, USA. ${ }^{17}$ Present address: Cancer Science Institute of Singapore, National University of Singapore, 14 Medical Drive, Singapore 117599, Singapore. ${ }^{18}$ Present address: Girona Biomedical Research Institute (IDIBGI), 17007 Girona 17007, Spain. These authors contributed equally: Jason J. Pitt and Markus Riester. These authors jointly supervised this work: Kevin P. White, Dezheng Huo, Olufunmilayo I. Olopade and Jordi Barretina. The original article can be found online at https://doi.org/10.1038/s41467-018-06616-0.Correspondence and requests for materials should be addressed to K.P.W. (email: kpwhite@uchicago.edu) or to D.H. (email: dhuo@health.bsd.uchicago.edu) or to O.I.O. (email: folopade@medicine.bsd.uchicago.edu) or to J.B. (email: jordi.barretina@gmail.com)
} 
(c) Open Access This article is licensed under a Creative Commons Attribution 4.0 International License, which permits use, sharing, adaptation, distribution and reproduction in any medium or format, as long as you give appropriate credit to the original author(s) and the source, provide a link to the Creative Commons license, and indicate if changes were made. The images or other third party material in this article are included in the article's Creative Commons license, unless indicated otherwise in a credit line to the material. If material is not included in the article's Creative Commons license and your intended use is not permitted by statutory regulation or exceeds the permitted use, you will need to obtain permission directly from the copyright holder. To view a copy of this license, visit http://creativecommons.org/licenses/by/4.0/.

(C) The Author(s) 2018 